\title{
Postmodernizmin Örgütteki İnsan Davranışlarına Yansıması
}

\section{İlknur ÖZTÜRK ${ }^{1}$}

ÖZ: 17. Yüzyllda, özellikle Avrupa'da meydana gelen teknolojik ve ekonomik alandaki gelişmeler toplumları, modernleşme olarak adlandırılan bir değişim sürecine girmeye zorlamıştır. Modernleşme, eskisinden farklı olan yeni bir dünya düzeni anlamına gelmektedir. 1980'den sonra modern dönem yerini postmodern döneme birakmıştır. Illk olarak mimari alanda kullanilan postmodernizm daha sonra sosyoloji, psikoloji ve yönetim $v b$., pek çok alanda kullanilmaya devam etmiștir. Insan; üretimin, rekabetin ve bilginin vazgeçilmez bir unsurudur. İşletmelerin içinde yaşadığ dönem ise bilginin ön plana çıktığl postmodern dönemdir. Postmodernizm, modernizmin ötesine geçmek anlaminı taşıdı̆̆ için, insan özellikleri de modernizmin ötesine geçmiştir. Bu çalışmada, postmodernizm kavramsal ve tarihsel yönü ile çeşitli yazarların görüşlerine yer verilerek ele alınmıştır. Bu süreç içerisinde değişime uğrayan insan özellikleri ve bu değişimin örgütteki insan davranışlarına yansıması incelenmiştir.

Anahtar Kelimeler; Modernizm, Postmodernizm, Postmodern Insan

JEL Kodu: D23, O15

\section{Reflection of Postmodernism on Human Behavior in the Organization}

\begin{abstract}
In the 17th century, especially with the developments in the technological field in Europe, economic growth forced the societies to enter into a process of change called modernization. Modernization means a new world order that is different from the old one. After 1980, modern period was replaced by postmodern period. Postmodernism, which was first used in architecture, then continued to be used in many fields such as sociology, psychology and management. Human is an indispensable element of production, competition and knowledge. The period in which the enterprises live is the postmodern period in which information comes to the fore. Because postmodernism means going beyond modernism, human characteristics have gone beyond modernism. In this study, the conceptual and historical aspects of postmodernism were discussed with the opinions of various authors. In this process, the changes in human behavior and human characteristics in the organization were examined.
\end{abstract}

Keywords: Modernism, Postmodernism, Postmodern Human

JEL Codes: D23, O15

Geliş Tarihi / Received: 28/02/2019

Kabul Tarihi / Accepted: 19/03/2019

\footnotetext{
${ }^{1}$ Dr. Öğr. Üyesi, Çağ Üniversitesi, İktisadi ve İdari Bilimler Fakültesi, ilknurozturk@cag.edu.tr, orcid.org/0000-0002-2079-0383
} 


\section{Giriş}

1970’li y1llarda başlayıp 1980 'den sonra popülaritesi artan postmodernizm; küreselleşme, yeniden yapılanma, kültür, sanat ve etik değerlerde çok şeyin değiştiğini ifade eden bir kavram olarak dikkat çekmektedir. Postmodern kavramıyla ilgili alan yazında çok sayıda çalışma olmasına karşın, bu kavramın tanımıyla ilgili fikir birliği olmaması, kavram belirsizliğine neden olmuştur. Postmodernizmin, modernizimden farklı bir süreci ifade edip etmediğini anlamak için, önce modernizmi irdelemek gerekir. Modernizim; yenileşme, aydınlanma, eskiyi geride bırakma davranışlarını ifade eden bir dönemi tanımlamaktadır. Bu yenileşme akımı ekonomi, üretim, sanat gibi pek çok alanda etkisini göstermiştir.

Postmodernizm kavramı modern kelimesi ile ilişkili olarak karşıt, sonrası veya benzeri şeklinde ifade edilmektedir. Postmodernizm, modernizmden etkilenerek ondan hareketle konumlanmaktadır. Bundan dolay1, postmodernizmi anlayabilmek için modernizmi anlamak gerekir (Erdemir ve Koç, 2010: 27). Postmodernizm ise bütün bu değişimlere karşı koyma onları reddetme davranışıdır (Alevok İzci ve Akkuş, 2017:309). Post kelimesi bugün İngilizcede kullanış şekliyle iki anlam taşımaktadır. Birincisi, Latince kökenli sonra-sonrası anlamına gelir. İkinci anlamı ise bir eklenti, bir ekleme demektir. Postmodernizmin, karşı koyma, tepki gösterme gibi eylemleri içeren, herhangi bir anlamı yoktur (Odabaşı, 2009: 23). Yapılan tanımlar bağlamında postmodernizm modernlikten sonrası anlamının yanında modernliğe karşı koyma eylemi olarak da ifade edilmektedir.

Postmodernizmin örgütteki insan ilişkilerine yansımasının incelendiği bu makalede, öncelikle modernizm ve postmodernizm kavramları üzerinde durularak söz konusu kavramların alan yazında nasıl değerlendirildiği ve insan ilişkilerine yansıması üzerinde durulmuştur. Makalenin temel amacı postmodern dönemin insan ilişkileri üzerindeki etkilerini incelemek ve söz konusu dönemin insan davranışlarında nasıl bir değişime neden olduğunu ortaya koymaktır.

\section{Modernizm ve Postmodernizm Kavramları}

Modern kelimesi Latince "modernus" haliyle 5. yüzyılda Hıristiyan dünyasını Romalı ve Pagan geçmişinden ayırmak için kullanılmıştır (Kızılçelik, 1994: 87). Neo-klasik yönetim düşüncesi, İkinci Dünya Savaşı yıllarından itibaren Modern Yönetim Düşüncesine dönüşmeye başlamıştır (Genç, 2007: 52). Modernleşme; tarımsal üretim ve küçük çaplı el sanatlarına dayalı bir yapıdan sanayileşmiş, şehirleşmiş, okuryazarlık oranının artmaya başladığı, kitle iletişim ve ulaşım araçlarının geliştiği, dinamik bir yapıya geçiş olarak tanımlanabilir. Modern dönemde baskın olan özellik, tarıma dayalı toplumdan, sanayiye dayalı topluma geçiş olarak ifade edilmektedir (Aslan ve Yılmaz, 2001: 94). Modernizm; yeni bir dünya düzenini, kültürel olarak toplumların değişmesini ve yeni bir yaşam tarzını ifade etmektedir. "Modernizm; olguculuk (pozitivizm), akılcılık, insanın özerkliği ve bilginin evrenselliği ilkelerini benimseyen" bir akımdır (Yıldırım, 2009: 381). 
Darwin, Marx, Taylor gibi düşünür ve bilim insanları modern dönemde, sosyal olayları uygulamalı olarak ifade etmeye çalışmışlardır. Kitle üretimi, kitle tüketimi ve kitle kültürü bu dönemin en temel özelliklerindendir. Modernist anlayış, rasyonel bir dünya düzeninin oluşturulması, aklın ve bilimin ön plana çıkmasıyla maddi gelişimi ve toplumsal refahı ilerletmeye çalışmıştır (Yeygel, 2006: 198).

Modernizm üretim ve yönetim alanında iki önemli gelişimin gerçekleşmesine neden olmuştur. Birincisi, 'yürüyen bantlar üzerinde yapılan kitle üretimi' ikincisi, 'bürokratik örgütlenme' biçimidir. Bu iki önemli gelişim beraberinde, çok miktarlarda ürün üretmeyi ve merkezi otoriteye bağlı ve bu otorite tarafindan yönetilen ve kontrol edilen insan varlığı kavramının önemini ortaya çıkarmıştır (Odabaş1, 2009: 28). Modernleşme, teknoloji ve sanayinin gelişmesi şeklinde kabul görmekte ve köyden kente doğru bir göçle birlikte ticaretin geliştiğini vurgulamaktadır. Sanayi devrimiyle birlikte modernleşme sürecine giren ülkeler için modernleşme, "değişmenin değişmesi" olarak sosyal ve kültürel çevrenin tamamını etkileyen, teknolojik, ekonomik ve çevresel değişimleri ifade etmektedir (Aslan ve Y1lmaz, 2001: 97).

Modernleşme sosyal, siyasal, ekonomik, kültürel gibi alanlarda, sanayileşen Batı toplumlarının sahip olduğu sistemlere sahip olabilmek için yapılan düzenleme ve değişikliklerin genel adıdır. Bu bağlamda, sosyal, siyasal, ekonomik, kültürel alanlarda modernleşmeden bahsetmek mümkün olmaktadır (Pektaş, 2006: 77). Modernizimden postmodernizme geçişte odak nokta, modernliğin eski olarak değerlendirilmesi ve modernliğin ötesine geçişi ifade etmesidir.

Postmodernizm kavramının Amerika kaynaklı olduğu ifade edilse de postmodernizmin doğuş yeri Fransa'dır. 1968 'de işçi sınıfı ve öğrenci hareketlerinin başarısız olması sonucunda Fransız aydınları sol düşünceden uzaklaşmaya başlamışlardır. Postmodernizmi kavramsallaştıran Fransız aydını François Lyotard'dır (Doyuran, 2013: 12). Jean François Lyotard, Kanada Hükümeti için hazırladığı raporun Postmodern Durum (The Postmodern Condition) başlığıyla yayımlanmasının ardından bu kavram akademik çevrelerde tartışmaların başlamasına neden olmuştur (Eraslan ve Şengün, 2018:182). Postmodernizm kavramı hakkında net bir fikir birliği yoktur. Postmodernlik, postmodernite, postmodernşleşme gibi kavramlar, birbirinin yerine kullanılan ve kafa karışıklığına neden olan terimsel ifadelerdir. Postmodern dönemin modernizimden bir kopuşu mu yoksa modernizmin bir uzantısı m1 olduğu yönünde değişik yorumlar bulunmaktadır (Özcan, 2007:263).

Knoornhof ve Villiers (1999) postmodernizmi; fikirlerin, felsefe, resim, sanat ve ekonomiye farklı bir bakış açışı sunduğu ve çoğu zamanda karmaşık bir yapısının olduğu bir terim olarak tanımlamıştır. Postmodernlik kavramı, kapitalizmle ilgili bir evreyi çağrıştırmaktadır. Bu yeni evrenin özelliği, sosyal, ekonomik ve kültürel olarak tüketime doğru bir akımı kapsaması ve kapitalizmin etkisinin, çok uluslu şirketler aracılığıyla gittikçe daha evrensel hale getirilmesidir. (Bocock 
1997: 83-84). Çabuklu (2003), postmodernliği modernlikten kesin bir kopuş olarak değil de modernliğin içinde kapalı ya da zayıf bir biçimde varlığını sürdürmeye çalışan eğilimlerin egemen olması şeklinde yorumlamıştır. Lyotard (1997), "gelin bütünlüğe karşı bir savaş başlatalım, gelin sunulamayana tanıklık edelim, farklılıklarl etkin kılalım" demektedir. Postmodernizm, birbirine benzeyen durumların yerine farklılıkları vurgulamaya çalışan bir dönemi ifade etmektedir. Postmodernizm; toplumun sahip olduğu değerleri, kültürleri, gelenekleri ve yaşam tarzlarında meydana gelen farkl1lıklar üzerine kurulu bir olgudur (Spicer, 2005: 671).

Postmodernizm, Türk Dil Kurumu Büyük Türkçe Sözlüğünde, “1. Modernist arayışın canlılığını kaybetmesinden sonra XX. yüzyılın ikinci yarısında ortaya çıkan çeşitli üslup ve yönelişlerin adı. 2. mim. Günümüz mimarisinde işlevsel olmayı bir tarafa bırakıp değişik yapı biçimlerini serbestçe kullanma eğiliminde olan üslup" olarak tanımlanmaktadır (TDK, 2019). Postmodernizme kesin olarak bir tanım yapılamaması ve bir kuram olarak da incelenememesinin nedeni; onun kavramsal bir kalıba sığmayacak kadar geniş bir anlama sahip olmasından kaynaklanmaktadır. Akademik çalışmalarda kullanılan materyaller ve kullanılan kaynaklar postmodern dünyanın vazgeçilmez bir unsuru olan internet ve bilişim teknolojileri sayesinde şekil almıştır. Bundan dolayı postmodernizm bilimsel çalışmalar üzerinde de önemli bir etkiye sahiptir (Eraslan ve Şengün, 2018:179).

Postmodern bakış açısı, 20. yy.'ın sonlarından itibaren her alanda değişimleri büyük oranda etkileyen bir kavram olarak kendini göstermiştir. Postmodernist düşünce mimari ve edebiyattan başka, politika, felsefe, psikoloji, sosyoloji, jeoloji, coğrafya, tarih, ekonomi, antropoloji, medya çalışmaları, hukuk vb., bir çok alanda da etkisini göstermektedir (Yeygel, 2006: 198).

\section{Postmodernizmin Örgütteki İnsan Özelliklerine Yansıması}

Modern dönemle birlikte, felsefî olarak akıl ve bilim; siyasal açıdan kimlik, milliyetçilik, liberalizm, sosyalizm; ekonomide sanayileşme, üretim, kapitalizm, emek, sınıf; kent yaşamı; sosyoloji, psikoloji; gazete, kitap, telgraf, yazı, kütüphane; demir yolu, otoyollar; mimarî yapılarda değişimler gibi pek çok alanda değişimler yaşanmıştır. Postmodern dönemle birlikte bu kavramlara küreselleşme, tüketim, eğlence, internet, cep telefonu, hız vb. gibi pek çok yeni şey eklenmiştir (Şimşek, 2014: 1). Sosyal, ekonomik ve teknolojik gelişmeler, eğitimli, zor beğenen, daha çok talep eden ve tüketim noktasında eğitimli bir tüketici grubunu ve bununla baş etmesi gereken bir iş dünyasını ortaya çıkarmıştır. Postmodern insan; ben odakl1, rekabetçi, bireyci, tüketim odaklı, farklı liderlik tanımı olan, teknolojiyle iç içe yaşayan ve bilgiyi iyi yöneten özellikleriyle ön plana çıkmaktadır.

Erich Fromm'un asistanı ve editörü olan Rainer Funk, postmodern insanın ruhsal olarak yönelimini anlama çabasının sonucunda "Ben ve Biz" adlı kitabını yazmıştır. Rainer Funk (2009)'a göre postmodern insanın temel özelliği 'Ben 
Odaklı" olmasıdır. Postmodern bireyin temel felsefesi "Ben, ben olduğum ölçüde benim"dir. Postmodern insan dünyanın merkezinde kendisinin olduğunu ve her şeyin kendisine göre şekillendiğini düşünmektedir. Ona göre, "Biz" duygusunun içinde dahi "ben" duygusu vardır. Bencilliğin bir sonucu olarak postmodern insanda kurumsal bağlılık, aidiyet duygusu zayıflamaya başlamıştır (Funk ve Tanyeri, 2013). Bu görüşe karş1 Erdemir (2006), postmodern dönemde bireysel anlayışların kabul görmediğini ifade etmektedir. Postmodern ben odaklılık "aktif" ve "pasif" olarak ikiye ayrılabilir. Aktif olan taraf post modern kültürü üreten ve sunan taraf iken, pasif taraf, söz konusu kültürü tüketen ve yaşayan taraftır. Örneğin bir eğlence programının yapımcısı ya da sunucusu aktif taraftayken, onu izleyen taraf pasif pozisyondadır. (Bayalan, 2012).

Değişen çevre koşulları bağlamında, rekabet ve belirsizlik durumunda örgütler, varlıklarını ve karlılıklarını sürdürebilmek için insan faktörünü önemli bir kaynak olarak görmeye başlamıştır. Bu süreç içerisinde, gerekli olan bilginin zamanında ve yerinde temin edilmesi, işlenmesi ve dağılımı önem arz etmektedir. Bununla birlikte kullanılan bilginin yenilik getirecek düzeyde olması ve yeni bilgi yaratımı ön plana çıkmıştır (Yıldırım, 2010:1331). Bu bağlamda, insanların örgütler için önemli bir kaynak olmas1, bilgiyi elinde bulundurmas1, kullanması ve yeni bilgi yaratması özelliğinden gelmektedir.

Modern dönemin reklamları, ürün ve özellikleri üzerine odaklanırken, postmodern dönemde reklamlar yerini anlamlara, sembollere ve kullanılan postmodern reklamlara bırakmıştır. Bu değişimin temel nedeni ise, "tüketim"e yüklenen anlamın değişmesidir (Özoran Artan, 2017: 2283). Kadın ve erkek olarak cinsiyet bağlamında, erkek üretmeyi temsil ederken, kadın ise tüketmeyi temsil etmektedir. Postmodernizm bu sinıflandırmaları reddetmektedir. Üretim yapmak kadar tüketimi de kabullenmekte ve bu cinsiyet ayrımını anlamsız bir sınıflandırma olarak görmektedir (Odabaşı, 2009:109). Tüketimcilik kavramı, batılı ve diğer toplumlarda yaşayan milyonlarca kişinin günlük yaşamında ve günlük tüketim uygulamalarında kapitalizmi meşru hale getiren bir ideoloji haline dönüşmüştür. (Bocock, 1997: 120). Tüketim ve alışverişin sonucu olarak bireyler kimi zaman statü sahibi olurken kimi zaman farkında olmadan kimliklerini ele vermektedirler. Tüketiciler, tüketim ve alışveriş esnasında isteklerini ön plana çıkarmayı arzu etmektedirler. Bu durum ise ürünün sembolik hale dönüşmesine neden olmaktadır (Batu ve Tos, 2017:1012). Böylece tüketim alışkanlarına göre, bireylerin kimlikleri ortaya çıkmakta ve bu durumun getirileri bireyde, büyük bir mutluluğa dönüşmektedir.

Postmodernizm ve küreselleşme ile birlikte, kitle iletişim araçlarının kullanımı ve medya gibi faktörlerin de etkisiyle, insanların üretim ve tüketim şekillerinin değişmesi sonucu toplumsal sınıflar arasındaki farklar daha da belirginleşmiştir (Batu ve Tos, 2017: 1016). Üretimin ve üretim şeklinin değişmesi ve küreselleşme olgusunun insanlar tarafindan benimsenmesi, postmodern dönemde tüketim kültürünün yerleşmesine neden olmuştur. Alış-veriş merkezlerinin artması 
sonucu, bu kapalı mekânların tüketicilere sunduğu hizmetler ile birlikte, postmodern insan daha fazla tüketim odaklı hale gelmiştir.

Postmodern dönemde, insanlar maddi olarak bir tatmin aramak yerine, psikolojik veya simgesel bir tatmin aramaya yönelmektedir. İnsanları cezbeden imajların, göstergelerin ve simülasyonların etkisiyle gerçek olmayan bir tüketim arzusu içinde olmalarıdır. Bu bağlamda insanların tükettiği her şey maddi unsurlardan ziyade onların simgeleridir (Özcan, 2007:269). Bu açıdan bu dönemin üretim toplumu yerine tüketim toplumu olarak adlandırıldığını söyleyebiliriz.

Postmodern dönem hız üzerine kurulmuş karmaşık bir süreci ifade etmektedir. Bu süreçte insan, her şeye yetişme kaygısını taşıdı̆̆ için acelesi vardır. Postmodern toplum tüketim ve eğlence toplumu olarak ifade edilmektedir. Hipermarketler, tatil ve eğlence yerleri insanların gerçeklerden kaçarak sadece tüketim yaptıkları yerler haline gelmiştir ve kişi ancak tükettiği kadar kişidir algısı yerleşmiştir (Pektaş, 2006: 8). Postmodern dönemde yaşanan ilişkiler ise kısa ömürlü, küçük, uçucu ve her an bozulabilme özelliğiyle birlikte, zevklere, deneyimlere ve duygulara önem veren özellikte taşımaktadır (Odabaşı, 2009: 83). Küreselleşme, ekonomik, sosyal, siyasal, teknolojik açıdan pek çok yeniliği getirmesinin yanında, hem bireysel hem de toplumsal hayatı etkileyen sorunların doğmasına da neden olmuştur. Bu süreç, insan hayatına yön veren bazı değerlerin yok olmasına, manevi açlık, amaçsızlık, yabancılaşma gibi problemlerin doğmasına da neden olmuştur (Altıntaş, 2012: 32). "Postmodern insan kolektif aidiyetlerden uzak, yalnı insandır. Bu yeni insan biçimsizdir, aklşkan, durumsal ve esnektir" (Güven, 2015:266).

Postmodernizmin iş hayatına etkilerinden biri de rekabetçilik kültürüdür. Postmodern insan; geleceğin belirsiz ve riskli olduğu iş hayatında, rakipleriyle rekabet edebilmek ve yaşamını sürdürebilmek için rekabetçi kimliğe bürünmek zorunda kalmıştır. Bu rekabetçilik kültürü bireyde, bilgi paylaşımı konusunda da rekabetçi davranarak bilgi paylaşımını azaltma yolunu tercih etmesine neden olmuştur. Postmodern insan daha hırslı ve bilgiyi iyi yöneten bir kimlikle rekabetine devam ederek kariyer ilerleyişinde rakiplerini geride bırakma arzusu içerisindedir.

Küreselleşme ve rekabetin bir sonucu olarak çevresel, örgütsel ve bireysel boyutlardaki gelişimler liderlik konusuna bakışı da etkilemiştir. Postmodern dönemde, geleneksel liderlik tanımları yerini karizmatik, etkileşimci, serbestiyetçi, vizyoner ve dönüştürücü liderliğe bırakmıştır (Yeşil, 2016: 164). Etkileşimci liderlik; liderin takipçileri ile olan ilişkilerinde gelenekselliğin dışına çıkarak iyi bir etkileşim süreci oluşturması ve gelişimlerini üst seviyeye taşıyarak, hedefler doğrultusunda belirli sorumlulukları almasıdır (Işık, 2014: 42). Vizyoner liderlik; örgütün tamamında veya bir bölümünde gerçekçi, güvenilir, çekici bir gelecek vizyonu yaratabilme ve ifade edebilme yeteneğidir. Vizyoner liderlik, işgörenlerini vizyon ile motive etmeye çalışan liderliktir (Tekin ve Ehtiyar, 2011:4010). Weber (1995) karizmay1, doğaüstü, insanüstü ve istisna bir gücü olan 
insan özelliği olarak tanımlayarak sıradan insanların lider olamayacağını ifade etmiştir. Karizmatik liderlik, bu kişilik özelliğine sahip olan liderlerdir.

Postmodern yönetici/lider karşıt olanı dışlamaz, onları anlamaya çalışır. Karşılaştığı bir sorunda tek yönlü bakış açısını ve problemin tek bir çözüm yolu olduğunu kabul etmez. Postmodern lider, her kararı sorgulayan, düşünen ve farklı açılardan değerlendirmeye çalışan özelliktedir. $\mathrm{Bu}$ bağlamda; postmodern yöneticinin gelişmiş bir ego ve benlik kavramına sahip olması gerekmektedir. (Sezgül, 2010: 244). Postmodern dünyada kurallar yoktur, kuralsızlık vardır. Postmodern liderler, kuralların olmadığı bir dünyada hayatta kalmak için ve kendilerini geliştirmek için, kendi özyapılarına dayalı ilkelere ihtiyaç duymaktadırlar (Sezgül, 2010: 248). Bu kapsamda değerlendirildiğinde, postmodern liderler, geleneksellikten uzak, vizyonu geniş, riskli durumlarda iyi yönetim tarzı sergileyen liderlerdir. Örgütte çalışan işgörenler ise bağlı oldukları liderleri bu özelliklerle değerlendirerek, beklentilerinin bu yönde karşılanmasını beklemektedirler.

Postmodern dönemde, katı hiyerarşik yapılar yerini daha esnek yapılara bırakmıştır. Çalışan ve yöneticiler arasındaki sınırlar ortadan kalkmış, çalışanlar yönetim sürecine dâhil edilerek sistemin bir parçası haline getirilmiştir. Çalışanlar bilgi ve iletişim teknolojisiyle daha sıkı ilişki kurarken, ortaya çıkan vasıflı ve vasıfsız işgücüne dayalı ücret sistemleri oluşturulmuştur (Kırılmaz ve Ayparçası, 2016). Üretim sisteminin değişmesi, işletme süreçlerinde değişime neden olarak işi yapacak olan bireyde de değişimleri beraberinde getirmiştir. Yönetim alanında önemli yeri olan Drucker (1980), günümüzdeki gibi yaşanan çalkantılı ortamlarda, yönetim faaliyetinin değişmediğini, ancak işletmeler üzerinde yeni baskılar oluşturduğunu ifade etmiştir (Koçel, 2010:348).

Postmodern çağda, mekan, zaman, insan ilişkileri ve emek anlamı da değişime uğramıştır. $\mathrm{Bu}$ değişimler, doğal olarak insan ve insanla ilgili beklentileri de değiştirmiştir. Postmodern toplumlarda eleştiren, yaratıcı, problem çözme yeteneği yüksek, bilgi ve iletişim becerileri iyi, farklı durumlara uyum sağlayabilen, işbirliği yapabilen ve araştıran bireyler önceliklidir. Gelecek dönemde, özgüveni, öz motivasyonu, kendini ve sınırlarını tanıyan ve özdenetim yeteneği iyi olan bireyler daha başarılı bireyler olacaktır (Şahin, 2004: 9).

\section{Sonuç}

Postmodernizm başta mimari alan olmak üzere, politika, felsefe, psikoloji, sosyoloji, coğrafya, tarih, ekonomi, medya, hukuk, yönetim vb., pek çok alanda etkili olmuştur. Küreselleşmeyle birlikte her alanda yaşanan değişimler, postmodern kavramını gündeme getirmiş ve bununla birlikte insan hayatında da değişiklikleri zorunlu kılmıştır. Postmodern dönemde insan; bireyci, tüketici, rekabetçi, hırslı, teknolojiyle iç içe yaşayan, zevkleri ve tercihleri farklılaşmış, bilgiyi daha iyi yöneten bir varlık konumuna gelmiştir. Hem yöneticiler ve liderler 
hem de çalışanlar bu değişimlerden etkilenen taraf olarak değişimlere ayak uydurmak zorundadırlar.

Postmodern insan yaşamını teknolojiyle içi içe olarak sürdürmektedir. Bu durum ise, bireyin yalnızlaşmasıyla birlikte sosyal ilişkilerinin zayıflamasına neden olmaktadır. Teknolojinin insanlara son yıllarda sunduğu hizmetlerden biri olan sosyal medya, gittikçe yalnızlaşan postmodern insanın, yalnızlık duygusunu gidermeye yarayan en önemli araçlardan biri olarak işlev görmektedir ki bu durum, aile, iş arkadaşları vb., sosyal grupların da ihmal edilmesine neden olmaktadır. Bu değişimler gösteriyor ki gelecek dönemde insan daha yalnız, sosyal ilişki kuramayan ve yalnızlığını sosyal medya üzerinde tatmin etmeye çalışan bir varlık haline dönüşecektir.

Postmodern dönemin en dikkat çeken tarafı ise tüketim kültürünün yerleşmiş olmasıdır. Ürün çeşitliliği arttıkça birey, isteklerini ihtiyaç haline dönüştürerek daha fazla tüketim yapma arzusu içerisine girmiştir. Bu durum, daha fazla tüketen birey için, daha fazla ürün ve hizmet çeşitliliğinin artmasına neden olmaktadır. Sonuç olarak daha fazla tüketim, daha fazla üretim döngüsünü gittikçe hızlandırmaktadır. Günümüzde istekler, ihtiyaçlar, sosyal ve ekonomik değişimler beraberinde yeni alışkanlıkları getirmiştir. Ortaya çıkan yeni yaşam koşulları, toplumsal değerlerde de değişimlere neden olmaktadır. Postmodern dönem bu değişimleri meydana getirerek toplumun bir parçası olan insan faktöründe de, yeni alışkanlıkları ve yaşam tarzlarını ortaya çıkarmıştır. Tüketim odaklı insan, zamanla hiçbir şeyden zevk almayan, sadece tüketme arzusu içinde olan ve beklentileri her geçen gün artan bir insan modeli oluşturacaktır.

K1saca; postmodern insan, tükettikçe mutlu olan, rekabetçi, eğlenmeyi seven, değişimlerden hoşlanan, daha özgürlükçü, teknolojiye dost, motivasyonu yüksek, bilgiyi iyi yöneten ve toplumsal olaylara duyarsız hale gelmiştir. Bayalan (2010) dediği gibi, "acıdan kaçan ve kendine yabancılaşan, kendi "ben" ine hapsolan insan"!

\section{Kaynaklar}

Alevok İzci, N. ve Akkuş, B. (2017). Modernizm, Postmodernizm ve Türkiye'de Kamu Yönetiminde Uygulamaları. Recep Tayyip Erdoğan Üniversitesi Sosyal Bilimler Dergisi, 6, 309-324.

Altıntaş, E. (2012). Bireycilik ve Toplumculuk Tartışmaları Bağlamında Değerler Eğitimi Yaklaşımları. Değerler Eğitimi Dergisi, 10(24), 31-54.

Aslan, S. ve Yılmaz, A. (2001). Modernizme Bir Başkaldırı Projesi Olarak Postmodernizm. C.Ü. Iktisadi ve İdari Bilimler Dergisi, 2(2), 93-108.

Batu, M. ve Tos, O. (2017). Tüketim Kültürü Odağında Modernizm ve Postmodernizmin Karşılaştırılması. Gümüşhane Üniversitesi İletişim Fakültesi Elektronik Dergisi, 5(2), 991-1023. 
Bayalan, Y. (2010), Ben ve Biz Postmodern İnsanın Psikanalizi. http://www.aktuelpsikoloji.com/artikel.php?artikel_id=1045. (Erişim Tarihi: 25/01/2019).

Bocock R. (1997). Tüketim, Çev. İrem Kutluk Dost Kitabevi Yayınları: Ankara.

Çabuklu, Y. (2003). Postmodern Toplumda Kriz ve Siyaset, Kanat Yayınevi: İstanbul.

Doyuran, L. (2013). Küresel Yeni Dünya Düzeninde Postmodern Söylem. Ulakbilge Sosyal Bilimler Dergisi, 1(1), 10-35.

Eraslan, H. ve Şengün, H. İ. (2018). Postmodernizm Akımı Ve İşletme Yönetimine Etkileri. USOBED Uluslararası Batı Karadeniz Sosyal ve Beşeri Bilimler Dergisi, 2(2), 178-193.

Erdemir, E. (2006). Postmodernizmin İşletme Yönetimine Etkileri: Kavramsal Bir Çözümleme. Hukuk, Ekonomi ve Siyasal Bilimler Aylık Internet Dergisi, Sayı 32, Haziran.

Erdemir, E. ve Koç, U. (2010). Postmodernizm ve Komplekslik: Örgüt Kuramı Bağlamında Paradigmatik Bir Tartışma. Eskişehir Osmangazi Üniversitesi IIBFF Dergisi, 5(1), 25-48.

Funk, R., \& Tanyeri, Ç. (2009). Ben ve Biz: Postmodern Insanın Psikanalizi. Yap1 Kredi Bankası Yayınları.

Genç, N. (2007). Yönetim ve Organizasyon. Seçkin Kitabevi, İstanbul.

Güven, S. (2015). Postmodern Kimliklerin Kurulumu. Selçuk İletişim, 9(1), 266286

Işık, N. (2014). Liderlik Yaklaşımları ve Hizmetkâr Liderliğin İşgörenlerin Organizasyonel Bağlllıklarına Etkileri. Yayımlanmamış Doktora Tezi, Bahçeşehir Üniversitesi Sosyal Bilimler Enstitisü.

Kırılmaz, H., ve Ayparçası, F. (2016). Modernizm ve Postmodernizm Süreçlerinin Tüketim Kültürüne Yansimaları. Insan ve Insan Bilim Kültür Sanat ve Düşünce Dergisi, 3(8), 32-58.

Kızılçelik, S. (1994). Postmodernizm: 'Modernlik Projesine' Bir Başkaldırı. Türkiye Günlüğ̈̈, 30, 90-105.

Knoornhof, C., Villiers, CJ de (1999). Postmodernism and Accounting: Mirror or myth? Meditari Accountancy Research, 7, 145-164.

Koçel, T. (2010). İşletme Yöneticiliği. (12.Bask1). İstanbul: Beta Basım A.Ş.

Lyotard, J. F. (1997). Postmodern Durum. Ahmet Çiğdem (Çev.). Ankara: Vadi

Odabaşı Y. (2009). Postmodern Pazarlama. Media Cat Kitapları. İstanbul. 
Özoran Artan, B. (2017). Modernite ve Postmodernite Kavramları Çerçevesinde Reklamlar: Hürriyet Gazetesi Örneği. Ulakbilge, 5(19), 2261-2286.

Özcan, B. (2007). Postmodernzmin Tüketim İmajları. Fırat Üniversitesi Sosyal Bilimler Dergisi, 17(1), 261-273.

Pektaş, H. (2006). Moda ve Postmodernizm. Yayımlanmamış Doktora Tezi, Selçuk Üniversitesi Sosyal Bilimler Enstitüsü.

Sezgül, İ. (2010). Liderlik Ve Etik: Geleneksel, Modern Ve Postmodern Liderlik Tanımları Bağlamında Bir Değerlendirme. Toplum Bilimleri, 4(7), 239-251.

Spicer, M. W. (2005), Public Administration Enquiry and Social Science in the Postmodern Condition: Some Implications of Value Pluralism. Administrative Theory \& Praxis, 27(4), 669-688.

Şahin, İ. (2004). Postmodern Çağ ve Hümanist Eğitim. XIII. Ulusal Eğitim Bilimleri Kurultay1, 6-9.

Şimşek, M.E. (2014). Moderniteden Postmoderniteye Uzanan Bir Köprü: Zygmunt Bauman. Yayımlanmamış Yüksek Lisans Tezi, Erzurum: Atatürk Üniversitesi Sosyal Bilimler Enstitüsü.

Tekin, Y. Ve Ehtiyar, R. (2011). Başarının Temel Aktörleri: Vizyoner Liderler Visionary Leaders: The Major Actors Of Success. Journal of Yaşar University, 24(6), 4007-4023.

Türk Dil Kurumu. (2019). Büyük Türkçe Sözlük: Güncel Türkçe Sözlük. http://www.tdk.gov.tr. (Erişim Tarihi: 03/01/ 2019).

Weber, M. (1995). Toplumsal ve Ekonomik Örgütlenme Kuramı (Çev. Özer Ozankaya). Imge Kitabevi, İstanbul.

Yeşil, A. (2016). Liderlik ve Motivasyon Teorilerine Yönelik Kavramsal Bir İnceleme. Uluslararası Akademik Yönetim Bilimleri Dergisi, 2(3), 158-180.

Yeygel, S, (2006). Postmodern Toplumsal Yapının Pazarlamaya Getirdiği Yeni Boyut: Topluluk Pazarlamas1 (Tribal Marketing). Bilig, 38(Yaz), 197-228.

Yildırm, M. (2009). Modernizm, Postmodernizm ve Kamu Yönetimi. Uluslararası Insan Bilimleri Dergisi, 6(2), 380-397.

Y1ldırım, M. (2010). Kamu Yönetiminde Bilgi Yönetiminin Gerekliliği Üzerine Bir İnceleme. Uluslararası İnsan Bilimleri Dergisi, 7(1), 1311-34. 